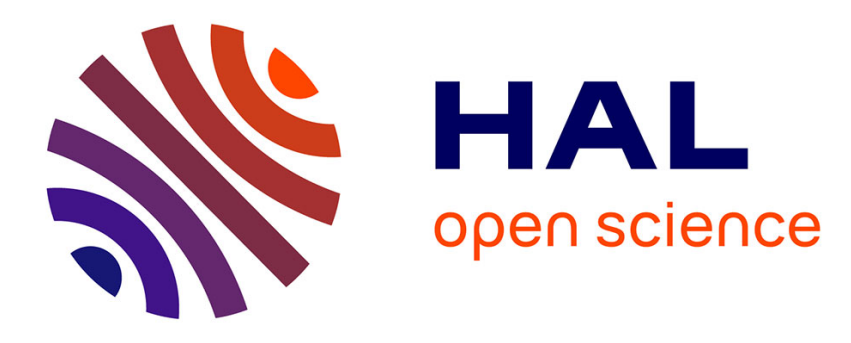

\title{
Modelling urban trajectories: the subjective biography of a scientific question
}

Denise Pumain

\section{To cite this version:}

Denise Pumain. Modelling urban trajectories: the subjective biography of a scientific question. Sajous P.; Bertelle C. Complex Systems, Smart Territories and Mobility., Springer, pp.1-14, 2021, 978-3-03059304-9. 10.1007/978-3-030-59302-5_1 . halshs-03326135

\section{HAL Id: halshs-03326135 \\ https://shs.hal.science/halshs-03326135}

Submitted on 25 Aug 2021

HAL is a multi-disciplinary open access archive for the deposit and dissemination of scientific research documents, whether they are published or not. The documents may come from teaching and research institutions in France or abroad, or from public or private research centers.
L'archive ouverte pluridisciplinaire HAL, est destinée au dépôt et à la diffusion de documents scientifiques de niveau recherche, publiés ou non, émanant des établissements d'enseignement et de recherche français ou étrangers, des laboratoires publics ou privés. 
Pumain D. (2021) Modelling urban trajectories: the subjective biography of a scientific question, in Sajou P. Bertelle C. (eds) Complex Systems, Smart Territories and Mobility. Springer, Understanding Complex Systems series, pp 1-14.

\title{
Modelling urban trajectories: the subjective biography of a scientific question
}

Denise Pumain

\begin{abstract}
This short article provides a kind of egocentric and longitudinal state of the art of a geographical questioning on the size and evolution of cities. The different stages in the construction of an evolutionary theory of systems of cities are recalled, punctuated by the questions that gave rise to it and by the methods that made possible its formalization. The investigations were at first based on the statistical analysis of empirical data bases about the geographical distribution of urban growth and the accompanying socio-economic transformations. Stylised facts were identified and used for revisiting the classical models of the hierarchical and functional organization of urban systems and enriching them with dynamic versions. Multi-agent modelling first made it possible to reconstruct the demographic and economic trajectories of cities. Then, artificial intelligence methods (evolutionary algorithms and intensive computing) were used to test the main hypotheses of the evolutionary theory. Although presented here from a personal perspective, all steps of research were produced through fruitful collective work.
\end{abstract}

Keywords: cities; system of cities; evolutionary theory; complex systems; modelling; Zipf; Gibrat; multi-agent models;

\section{Introduction}

This article is a subjective account of the search for a scientific explanation of the geographical process of urban growth and evolution of city sizes. I summarize here a questioning that has been going on for some fifty years. I have chosen to construct this narrative along the lines of the history of ideas. But the path is obviously more complex, because the advancement of ideas in science is closely linked to the parallel evolution of the litterature, the more or less directed series of readings and meetings and the progress of technical instruments, and is of course mixed with the sociology of research laboratories... Moreover, all the works whose intellectual progress I report here are not only mine but have been collective undertakings and achievements. I give here only a very abridged version where it is impossible to do justice to the many persons who provided valuable and brilliant insights for that research. I apologize in advance towards the persons who may feel neglected in recognizing their contribution, and all errors are my own. 
While composing this paper I notice that it may reveal an implicit constraint from the availability of methods on the course of research, although the guiding principle was not an improvement in methodology but a quest towards a more secure formalization of the major stylized facts already observed about the diverse evolution of cities. Indeed, a first step was to elucidate the connection between statistical models of city size distribution with statistical models of urban growth based on the observation of urban populations (section 2). Second, deeper investigations of the underlying socio-economic profiles were made possible through using multivariate analysis, leading to a new evolutionary interpretation of the major sources of differences among cities (section 3). Third, a possible generalization was proposed in the construction of the evolutionary theory of urban systems (section 4). Several generations of dynamic models under mathematical or computational forms were then used for reconstructing observed trajectories of the urban demographic and socio-economic attributes. Simulations and advanced exploratory methods for their validation ultimately enabled to test and recognize the main principles of the evolutionary theory of urban systems both as necessary and sufficient proposals (section 5). In conclusion I present a simplified view of the three major dynamic regimes that occurred during the 8000 years geo-history of urban systems.

\section{Zipf and Gibrat: determined individual actions, a random collective outcome, or is it the reverse?}

I began the book "La dynamique des villes" (Pumain 1982) with the following paradox:

"While a process of urbanization is progressing, while the urban population is increasing, in quantity and proportion to the total population, while the number of cities and their size continue to grow, while this process is accompanied by very significant changes in productive systems and in the living and housing conditions of populations, we observe a very large persistency in the relative positions of cities in the hierarchy of sizes, a persistence of functional specialization among urban areas, which is reflected in the rather uncertain and few assessments of urban planning policies (Bourne, 1975)". And I added: "this paradox of the maintenance of a certain structural identity of a group of cities over time, despite the vagaries of demographic and economic growth, deserves attention, both from a practical point of view and in terms of urban theory" (ibid, p.7).

Searching for an answer to this question with the statistical means and calculation tools available at that time went through a stage of building databases and testing simple models, which on the one hand provided a statistical summary of the shape of the distribution of city sizes, and on the other hand made it possible to characterize the growth process that ensured their evolution. The most abundant literature dealt with the city size distribution model, in particular Zipf's law, of which several statistical variants were proposed, but often tested on data that lacked rigor in the definition and delineation of urban entities. The diversity of the results obtained led to misunderstandings and uninformed discussions, which I have reported on several occasions in subsequent writings (Pumain 2012).

On the other hand, few authors at that time had considered the model of settlement size hierarchy proposed by Gibrat (1931), the lognormal law, which has the advantage of being testable in its generative process. The model in fact linked the shape of the distribution of city sizes to the process of spatially distributing the growth between cities. Constructing harmonized databases of all the cities (defined as urban agglomerations or urban functional areas) in a territory, observed at short intervals over a fairly long period of time thanks to census data, 
therefore made it possible to verify both the degree of adequacy of a theoretical model of urban hierarchies and the plausibility of the growth hypotheses predicted by the model. According to the process of «proportional » growth as described by Gibrat, it gives rise to a lognormal distribution of city sizes if urban growth rates are equiprobable whatever the city size and not correlated with previous rate. Brian Robson (1973) had tested it successfully on the evolution of urban agglomerations in England and Wales during the $19^{\text {th }}$ century. He mentioned however a few slight deviations between empirical observations and the pure stochastic model, which I also observed when testing it on French data $19^{\text {th }}$ and $20^{\text {th }}$ century (Pumain, 1982).

Although not quite perfect, the rather good quality of fit of the model made it a satisfying first approximation for summarizing the urban growth process. The contribution to urban theory was thus double: the model provides first a statistical explanation of the shape of urban hierarchies and second a better understanding of the persistency of their spatial pattern. This explanation could be admitted by geographers, but not by specialists of urban economics for whom the ranksize rule remained a "mystery" (Krugman 1996), mainly because economists wanted to derive it from a process that would be defined at the level of individual firms and persons (see section 4 for a more precise discussion on that point).

These first tests also enabled to convey a few messages that could be useful for practitioners:

- One can expect a statistical predictability of city growth and size on short time periods

- The largest metropolises are not «monstruopolises » but cities that have reached their size through a well identified growth process and that is generally quantitatively related to the population size of the country where they are located

- As the growth process is not deterministic at the scale of single cities, proactive adaptive strategies are always necessary for giving growth impulses from public or private governance. Such strategies may follow secure decisions imitating already successful changes experimented in other places, or more risked anticipation through launching innovations, within a general competitive process among cities of different sizes and functional specialization. As in other complex systems, co-opetition would provide more benefits at system level rather than the traditional historical urban rivalries.

- The spatial and hierarchical structures of urban systems are very robust over long periods of time, but they admit rather considerable variations in terms of inequalities in sizes according to the political history of the countries (Moriconi-Ebrard 1993). Despite the existence of a common generic model, the latter is neither a norm nor an optimum. It is merely the signature of the historical sustainability of urban systems as well as of their common dynamics.

\section{A discovery: the socio-economic co-evolution of cities}

Admitting that the distribution of city sizes, with its strong inequalities and its persistence over time, can be explained by a rather simple stochastic process of urban growth is a step forward in knowledge. It is a morphogenetic explanation, as the morphology of the system of cities is thus related to the dynamics of this system. But from the point of view of geographical theory it is a little frustrating since in this model intentional individual initiatives disappear because their result is random and cities are supposed to be independent from each other - which of 
course they are not. This also means taking the search for an explanation a step forward: why do cities grow all together in that way? What justifies that all well-connected cities in the same territory have on average the same growth rate over the long term, despite the great fluctuations observed in this growth spatially and over shorter periods of time?

A first idea would be to borrow the demographers' method known as the "components method", insofar as the growth of a population can be described as the sum of a natural balance and a migratory balance. The observation shows that migration makes the largest contribution to differentiating demographic increases among cities, particularly in periods of strong urbanization fuelled by a rural exodus, while the natural balance varies less from one city to another, depending on general demographic behaviour and the age-structured contributions of previous migrations. Geographically, migration conforms to the observations summarized by gravity models, with flows being proportional to the populations of origin and destination and inversely proportional to distance.

Considering this lead to searching for an explanation by investigating how migrations (that represent the attractiveness of cities) are linked to the jobs cities offer to the population. At certain periods, the fastest growing cities, which are the most attractive, are those where jobcreating and income-generating activities are developed. Geographers have a long tradition of classifying cities according to their activities and thus defining urban functions, or functional specializations (Pumain, Saint-Julien 1976). Multivariate analyses provide a synthetic description of the associations and exclusions of activities in cities. Among contemporary cities, the most striking difference separates two major families of cities, those with predominantly industrial bases and those oriented towards services, with a secondary differentiation playing on the more or less recent character of industrial and tertiary specializations. Looking at the relative stability, or slow evolution of that fundamental structure over a few decades, we found a surprising parallelism in the trajectories of individual cities: the qualitative and quantitative changes occurring in the social and economic composition of urban populations were almost the same in all cities (Pumain, Saint-Julien 1978). This incremental and distributed process of socio-economic change contributed to a kind of simple homothetic translation of the former hierarchical and functional structure of the urban system.

Moreover, each major factor that defines this multivariate structure could be related to subsets of activities and skills that were developed at a specific moment of time and had generated waves of marked urban specialization. In the French case the first factor was a reversal of the inequalities created by the first industrial revolution of the $19^{\text {th }}$ century (less industrialized cities had now the higher incomes, welcomed more of the new services and had become the most attractive in the second half of $20^{\text {th }}$ century), and the second factor ranked the cities according to their ability in having attracted both industrial and service modern activities that were developing during that period (Pumain, Saint-Julien, 1978). Such an interpretation was later confirmed on a further diversity of urban attributes (Paulus 2004) and recognized as providing a good description of the functional disparities of US cities (Paulus and Vacchiani-Marcuzzo, 2016) as well as in South Africa (Vacchiani-Marcuzzo 2016) or even China (Swerts, 2013).

Compared to the simplistic description of urban growth provided by Gibrat's model, several gains in explanation were attained with these results. First, it is not because they are statistically independent entities that cities grow roughly at the same rate, but on the contrary because they share the same kind of transformation of their economic and social profiles, as being part of a 
territory under common laws and societal regulations and processes. This is likely to happen because of the multiple connections ensuring a rapid communication of information between cities (see section 4). Second, the Gibrat's model when completed by including growth impulses from innovation waves and their hierarchical diffusion within the system of cities (Favaro, Pumain 2011) helps to better understand the recurrent deviations that were observed between empirical data on urban growth and Gibrat's stochastic model, i.e. a slight positive correlation between growth rates and city size (at the beginning of each innovation wave) and a persistency of high or low growth rates in the same cities over some periods of time. This also provides an understanding of the bifurcations in the trajectories of individual cities that are created by the major functional specialization, successively amplifying urban growth then urban decline according to the stage in the corresponding product cycles.

We were able to use that knowledge for developing an interpretation, which is better anchored in geographical urban theory, of the new frame of analysis proposed under the label of "scaling laws" by physicists (Bettencourt et al. 2007). Instead of imagining an urbanization process where largest cities would simply be a replication of smaller ones constrained by universal power laws ${ }^{1}$, we explain the level and observed variations in values of the exponents of urban scaling laws according to the stage of development of the considered urban attributes in the urban system (Pumain et al 2006 and 2009). Exponents of non-linear relationships between an urban attribute and city size are above 1 during the first stage of adoption of innovation in the urban system, when they are captured by and concentrate in the largest cities, and below 1 when they withdraw in smaller towns of cheaper land rents and wages after their stage of wide diffusion all over the system. Over time the exponent values evolve according to this theory (Paulus 2004; Finance and Swerts 2020).

Thus starting from an interpretation of a temporal multivariate analysis, we have made a "discovery" that was later confirmed with a series of different investigations. To summarize that discovery: size inequalities and qualitative socio-economic differences between cities are traces of their co-evolution (which is an interactive adaptation with feedbacks to the innovations they create). Is this a real discovery? Indeed, elements of the theoretical explanation were already there in urban geography, since the theory of hierarchical diffusion of innovations was proposed by the Swedish geographer Torsten Hägerstrand as early as 1952 (and 1967 for an English translation). This is another illustration of the spiral cumulativity of knowledge that characterize social sciences where new interpretations are never entirely new (Pumain, 2009).

\section{Construction of a multi-level ontology according to an evolutionary theory for urban systems}

The scientific objects of geographer's inquiry are not given but built. Some, however, such as the landscape or even the city, are more than others part of the common experience. As much as the city allows itself to be seen, described and felt by everyone, alongside the recurring exercises of definition and the multiple attempts to harmonize these concepts and their measurements, the higher level of the organization of cities in the territories appears only faintly in the consciousness of the ordinary public. Yet it is at this level that statistical regularities are most frequently observed, and the most similar in all parts of the world.

\footnotetext{
${ }^{1}$ This is not a well-adapted description since systems of cities are not ergodic, see Pumain 2010
} 
Using the vocabulary of complex systems sciences, we can say that observing the cities coevolution leads to the identification of a process of "strong emergence", which brings to light a "new" geographical object identifiable on a meso- or macro geographical scale, that of regional, national and even continental or global territories, which I call "system of cities". The ontology of urban systems characterize three relevant levels for observing urban populations, their activities and artefacts: at micro-level, urban citizens, firms and collective institutions have each specific attributes. The interactions between these diverse stakeholders over time lead to a first strong emergence of the object called "the city". A city has collective emerging properties that cannot belong to any individual of the lower level (such as the urban morphology, the centrality, the urban functions or a qualitative "ambiance"). At a higher geographical level, all kind of interactions between cities (either concrete as transfers of goods, persons and investments, or immaterial as exchanges of information between their variety of economic, cultural and political actors) generate over time interdependencies in cities' socio-economic evolution. The major emerging properties at that level are the regular hierarchical distribution of city sizes and the functional diversity of cities as well as their spatial organization. These properties are universal and characterize systems of cities all over the world.

It is clear here that this is not a "discovery", but an "invention" in the social sense, a construction according to the epistemological vocabulary. It is part of a spiral process of construction of knowledge (Pumain 2009) because it revisits the more static concept of the "general system of cities" described by the Saint-Simonian engineer Jean Reynaud as early as 1841, that was formalized under the headline "theory of central places" based on hypotheses about the economic behavior of consumers and service entrepreneurs by Walter Christaller (1933), many times documented in regional monographs under the expression "urban network" in the 1960s by French geographers who were disciples of George Chabot or Pierre George, considered in urban geography textbooks by Jacqueline Beaujeu-Garnier and Philippe Pinchemel (1963) and transferred to common representations in French spatial planning to define the policies of "métropoles d'équilibre" in the 1960s or "villes moyennes" in the 1980s. In the USA, the geographer Brian Berry coined the famous sentence "cities as systems within systems of cities" in 1964 and Alan Pred made historical analyses of innovation diffusion and growth in systems of cities (1973), he also scrutinized the evolution of variegated urban interactions in developed countries (Pred 1977).

What is new in the evolutionary theory of cities that I developed in (Pumain 1997) is in rooting these former insights within the theories of self-organizing complex systems. Urban systems are conceptualized as adaptive complex systems organized since long for sharing information, diffusing innovations, reducing uncertainties of local environments by making benefits from distant complementary resources. Cities and the systems they build through their interactions are socio-economic adapters in a rather continuous process of territorial competition. I suggested that the common features in the evolution of systems of cities have similitudes with the dynamics of other kinds of systems where an "order" at higher level is created through "fluctuations" at a lower level. To understand the compatibility of the "disorderly", "random" fluctuations of urban growth (this does not mean that these actions are irrational or inexplicable, but that they are impossible to describe in detail, for each element simultaneously, in the whole system defined at the higher observation level) with the persistence of the structure of that system, to reconcile the rapid dynamics of the micro level with the slow dynamics of the macro level, the self-organization theories propose mathematical models that we have experimented. These models represent by non-linear differential equations the temporal evolution of the state 
variables that define the macroscopic structure of the system, the microscopic interactions being represented by mathematical functions or by parameters. From this perspective, we lose the notions of uniqueness and non-reproducibility attached to historical objects, but we take into account the irreversibility of their particular trajectory. It is accepted that processes can be formalized, that geographical objects can have a "banal dynamics" in a historical trend that remains irreversible" (Pumain, 1998, p.364).

But the evolution of the social objects is not limited to that universal dynamics, significant differences do exist in the parameters that characterize the national or continental urban hierarchies. These have to be explained by the path-dependency that maintains over very long periods of time (it may be centuries!) their distinctive features according to the major historical circumstances that created them, such as the date and type of establishment of settlement systems ("Old" or "New" world), the type of territorial governance that shaped them (centralized or not), the steps of their development or the way they became inserted in the colonial empires and phases of globalization (Bretagnolle et al. 2007 and 2009). It seems that the current globalization of the economy, society, culture... generates ever growing interdependencies between cities all over the world and amplifies their co-evolution, consolidating the genericity of the concept of system of cities.

\section{Dynamic modelling: from reconstructing urban trajectories to testing the theory}

The principles of the evolutionary theory were translated into a series of dynamics models because we think that reconstructing past urban trajectories within their historical and geographical context is a first necessary step for testing the relevance of our theoretical explanation. It is also a condition for ensuring the quality of projections estimating future relative positions of cities within inter-urban competition, thus for adjusting intelligent urban policies. Many experiments were tempted, including at first mathematical models of systems of non-linear equations and then computational models of multi-agents systems (see Pumain \& Sanders 2013 for a review).

Despite the heuristic interest of self-organization theories and associated mathematical models, the practical application of such models in geography is proving difficult (Lombardo et al. 1988; Pumain et al.1989; Sanders, 1992). The models we had borrowed to the team around Prigogine in Brussels (Allen, Sanglier 1979) and around Haken in Stuttgart (Weidlich, Haag 1988) have taught us much about a variety of calibration strategies in the presence of non-linear interactions that were often causing too many bifurcations. But major limitations in their application were due to the lack of flexibility of systems of non-linear equations to represent spatial interactions. We have therefore fairly quickly resorted to multi-agent simulation models that allow an explicit reconstruction of these interactions, which are supposed to generate by their repeated operations the differentiated dynamics that characterize systems of cities (Sanders 2013). With the help of computer scientists, we thus designed the SIMPOP series of models that was conceived to explain the hierarchical differentiation of city sizes and their functional geodiversity. The implemented mechanisms between "agents" (i.e. collective agents that represent individual cities) are mainly: a proactive and selective propagation of innovations waves generated by interurban competition and emulation; a market exchange between urban functions; a hierarchical selection (top down and bottom up); the appearance of new urban functions (exogenous in first models); an expanding range of interurban interaction (as a result 
of space time contraction); path dependence according to the territorial boundaries that constrain urban interaction.

The first application of such a multi-agent system in geography (Bura et al. 1996) on a fictitious settlement system whose properties were inspired by the evolution of cities in the Rhône valley over 2000 years led to the following main results: an urban hierarchy cannot emerge if there are no spatial interactions; the emergence of a polycentric hierarchized system of cities can occur under a stochastic process of inter-urban exchanges even if starting from homogeneous initial conditions; but a renewed innovation flow is necessary for maintaining the structural properties of the system of cities over time. Such first applications were limited by the capacity of computing systems (our first model was restricted to deal with 400 settlements only and calibration was considered as satisfying after some 100 simulations), fortunately the computing speed and capacity have considerably increased since these pioneer times, only twenty five years ago!

A second SIMPOP model, built by another computer scientist, Benoît Glisse, enabled to inform some of the processes that generate the diversity of systems of cities, based on a comparison between Europe and the United States (Bretagnolle et al., 2010). A first version of the model, adjusted to the evolution of European cities over four centuries, had to undergo significant qualitative changes in order to be able to account for the evolution of American cities over three centuries: a system of "New World" cities was thus identified in its broad outlines, based on the necessary transformation of the rules of the multi-agent model representing the interactions between cities. It forced in particular to introduce the notion of a "pioneer front" for simulating the colonization of a territory by cities and their dependence on an external demand - that of the metropolis - to ensure the development of the system, in accordance with the dynamics revealed by the calibration on empirical data.

The results of experiments with this model also provided further advances in explaining the evolution of systems of cities, proving the importance of urban networks in generating more urban growth. Actually, until nowadays, the observed historical major dynamic trend leads to an increasing hierarchisation: the inequalities in city sizes are becoming larger than those that would be predicted with Gibrat's model, contradicting the theories predicting counterurbanization (Berry, 1976). A discovery that "global cities may exist since the Middle Age" has also been identified since the cities that are at the head of urban hierarchies always expand a significant part of their interactions beyond the boundaries of their own system (Bretagnolle, Pumain, 2010). We have verified in further studies including as well the BRICS countries that "metropolisation" and "simplification from below of urban hierarchies" (leading to "shrinking cities") are common dynamics trends observed in several systems of cities in the world (Pumain et al. 2015).

But it is from a much closer and more continuous collaboration between computer scientists and geographers that a qualitatively very important step forward was taken. Indeed, a major problem with multi-agent simulations was that of their validation, since the uniqueness of the solutions reached during their calibration, whether based on empirical data or theoretical hypotheses, cannot easily be guaranteed. The development of the OpenMOLE simulation platform allows the integration of sophisticated model validation processes, including genetic algorithms and access to parallel grid computing. We have been able to acquire more certainty in the quality of parameter estimation for a generic model, SimpopLocal (Schmitt 2014) 
dedicated to the emergence of cities during some 4000 thousand years after Neolithic with the help of the SimProcess platform developed by Sébastien Rey-Coyrehourcq (2015). Compared to the few hundred simulations that were available when estimating with trial and error "by hand" methods in the former experiments with Simpop models, it was possible to develop an almost exhaustive exploration of the space of parameters, through some 500 million replications of the same model (Schmitt et al., 2015). The theoretical hypotheses thus tested and assumed to lead to the emergence of a system of cities based on interactions propagating innovations between population centers could be considered not only as sufficient, but also as necessary to reconstruct an urban hierarchy and a right diversity of urban trajectories. A new procedure for the rigorous exploration of the behaviors of a model called "calibration profile" was developed for that precise purpose (Reuillon et al., 2015).

Such an outcome is important for the humanities and social sciences because it opens the door to providing proof when answering questions about complex social processes. A first step had been taken by the adoption of multi-agent models, allowing more flexible and diverse formulations than mathematical equations to represent part of these processes. However, the number of possible replicas of the simulations often remained too limited and the values estimated by calibration still too uncertain to constitute a sufficient validation of the assumptions introduced into the model. Even if the ambition of these models is never to produce an exact numerical result or one that would totally optimize only one aspect of the problem, we now have powerful exploration methods that describe all the dynamic behaviors of a model, that produce satisfactory process trade-offs leading to plausible solutions, and that detect whether the contributions of certain processes and parameters to these dynamics are truly effective or not. It seems to us that an important step has been taken in advancing modelling in the social sciences and humanities towards scientific accuracy and reproducibility.

The research program GeoDiverCity ${ }^{2}$ also paved the way for developing a new method of building simulation models aiming at taking into account not only the general urban dynamics for reconstructing common stylized facts but as well the major historical features that distinguish regions of the world. The MARIUS model designed by Clementine Cottineau and Paul Chapron with the help of the OpenMOLE simulation platform was designed to reconstruct the trajectories of cities within the boundaries of the territorial system of the former USSR (Cottineau 2014). In parallel the authors invented an incremental method for model building: from a hierarchy of factors explaining the differential urban growth that was revealed by statistical analysis of the observed trajectories of individual cities. They implemented first the simplest and more generic model of urban growth (i.e. a Gibrat's stochastic model without spatial interaction) then introduced more sophisticated mechanism of constraints on urban growth as well as some specific environmental conditions (Cottineau et al. 2015). At each step the computed deviation between expected shape of urban hierarchy and typology of urban trajectories and the computed ones helped to measure the retro-predictive capability of the model. For instance in that case it was important to introduce not only resource location for generating functional specialization but as well the political decision of large investments in these urban areas. A new geographical modelling is thus proposed, which operates at different levels of precision, according to an adjustable focus evaluating the degree of specificity of a

\footnotetext{
${ }^{2}$ ERC advanced grant GeoDiverCity 2011-2016 (PI Denise Pumain)
} 
particular evolution in a generic dynamic, for a given granularity of description (Cottineau et al., 2015).

\section{Conclusion: which future for urban systems?}

This paper has traced an intellectual path for the construction of a theory of the evolution of cities interacting as a system, based on empirical observation in various regions of the world and on mathematical and computational formalizations. The question is posed from a geographical point of view, which is interested in taking into account both general dynamics and regional specificities. The important regularities highlighted at the macro-geographical level of systems of cities and the very many previous works that discuss them explain why the theory has been able to be built up in a few decades to lead to generic formulations and transposable models, in what I have called an evolutionary theory of systems of cities. Indeed, since the main function developed by cities is to connect distant territories in order to exploit, share and develop their resources, the world's cities have always been constituted as systems of cities whose evolutions have become increasingly interdependent. The transformations of individual cities can be better understood in terms of co-evolution.

It seems to me that the evolution of cities can be summed up in three main regimes since their appearance some 8,000 years ago. The emergence regime, which lasted from 4 to 6,000 years, is characterized by the networking of cities that weave together a wide variety of interactions, but also by the difficult resilience of most cities, due to environmental hazards or predations or conflicts that lead to the periodic destruction or even disappearance of many of them. Even if the disparities in growth now associated with inequalities in demographic regimes and economic development remain extremely wide and fluctuating, total disappearances of cities have become very rare after 1500 and a process of co-evolution is beginning or being confirmed since at least a few centuries depending on the regions of the world observed. A second evolutionary regime characterizes thus the last two centuries, fueled by the industrial revolution and the demographic transition. It has allowed the development, without apparent constraint, of a world system of cities (about 60,000 urban agglomerations now have more than 10,000 inhabitants and concentrate half of the world population) which now link all territories and which has become considerably hierarchical (more than 50 agglomerations today are larger than 10 million inhabitants). Even if sub-systems still function largely on the basis of proximity, the concentration of populations and the multiplication of connections contribute to this global expansion of the system of cities. But the venue of a third regime is imminent in this dynamics, for two reasons: on the one hand, the increasing scarcity of planetary resources is becoming more and more a constraint that could hinder the further expansion of the system, on the other hand, the slowdown in foreseeable demographic expansion in the long term may call into question the dynamics of growth, concentration and hierarchization that has so far prevailed in the historical evolution observed. The ecological transition required to mitigate the Anthropocene's climate change appears as an "innovation" that the existing system of cities can help to achieve adopting, by transmitting top-down intergovernmental incentives and regulations, and bottom-up by disseminating inventions and initiatives carried out locally for these remediation. The urban future remains uncertain, but not necessarily catastrophic.

On the research side, it is important to continue model-building experiments with the successful methods that continue to develop. The major progress, apart from the possibility of validating hypotheses, is also due to the reproducibility of these experiments which the new methods 
favor, even for very complex models. Another possible source of innovation comes from the appearance of massive data on interactions between cities observed at micro scale. Most of the simulation models we have developed had to first estimate the interactions between cities in the most plausible way by inferring them from statistical and geographic models, since they could not be observed directly (Pumain 2008). The knowledge of capital movements between firms and foreign investments located in cities were already quite exceptional (Rozenblat 2018; Finance 2016). We can now hope to have better estimates of social exchanges based on direct observation of communications between people, even if this information is not always accessible and only partially provides information on the behavior of urban actors. Whether testing theoretical hypotheses or providing decision support for cities, the combination of sound empirical data and effective modelling methods is still needed to better understand the dynamics of systems of cities.

Acknowledgment: Partially translated with www.DeepL.com/Translator (free version)

\section{Références}

Allen P, Sanglier M, 1979, "A dynamic model of growth in a central place system" Geographical Analysis. 2 256-272

Berry B.J.L., 1964, Cities as Systems within Systems of Cities 1964, Papers in Regional Science, 13(1) $147-163$.

Berry, B. J. L. 1976. Urbanization and counter-urbanization (Vol. 11). Sage Publications, Incorporated.

Bettencourt, L. M., Lobo, J., Helbing, D., Kühnert, C., \& West, G. B. (2007). Growth, innovation, scaling, and the pace of life in cities. PNAS - Proceedings of the national academy of sciences, 104(17), 7301-7306.

Bourne L. 1975 Urban Systems: Strategies for Regulation. A Comparison of Policies in Britain, Sweden, Australia and Canada. London, Oxford University Press.

Bretagnolle A., Pumain D., Vacchiani-Marcuzzo C., 2007, Les formes des systèmes de villes dans le monde, in Mattéi M.-F., Pumain D. (dir) : Données urbaines, 5, 301-314.

Bretagnolle A., Pumain D., Vacchiani-Marcuzzo C., 2009, The Organization of Urban Systems, in : D. Lane, D. Pumain, S. Van der Leeuw, G. West (eds.), Complexity perspectives on innovation and social change, ISCOM, Springer, Methodos Series, Berlin, 197-220.

Bretagnolle A., Pumain D. 2010, Simulating urban networks through multiscalar space-time dynamics (Europe and United States, 17th -20th centuries), Urban Studies, 47, 13, 2819-2839.

Bura S. Guérin-Pace F. Mathian H. Pumain D. Sanders L. 1996, Multi-agent systems and the dynamics of a settlement system. Geographical Analysis, 2, 161-178.

Christaller,W. 1933. Die Zentralen Orte in Süddeutschland. Jena, Fischer.

Cottineau, C. (2014). L'évolution des villes dans l'espace postsoviétique. Observation et modélisations. Thèse de Doctorat, Université Paris 1 Panthéon-Sorbonne, Paris.

Cottineau C., Chapron P., Reuillon R., 2015, Growing models from the bottom up. An evaluation- 
based incremental modelling method (EBIMM) applied to the simulation of systems of cities, Journal of Artificial Societies and Social Simulation (JASSS), 18(4), 1-9.

Favaro J.-M. Pumain D. 2011, Gibrat Revisited: An Urban Growth Model including Spatial Interaction and Innovation Cycles. Geographical Analysis, 43, 3, 261-286.

Finance O. 2016, Les villes françaises investies par les firmes transnationales étrangères: des réseaux d'entreprises aux établissements localisés. Thèse de Doctorat, Université Paris 1 Panthéon-Sorbonne, Paris.

Finance O. Swerts E. 2020, Scaling laws in urban geography. Linkages with urban theories, challenges and limitations, in Pumain D. (ed.) Theories and Models of Urbanisation. Springer, Lecture Notes in Morphogenesis, 67-96.

Gibrat R. 1931, Les inégalités économiques. Paris, Sirey.

Hägerstrand T. 1967. Innovation Diffusion as a Spatial Process. Chicago, University of Chicago Press.

Krugman, P., 1996 Confronting the Urban Mystery. Journal of the Japanese and International Economies, X, 399-418.

Lombardo S, Pumain D, Rabino G, Saint-Julien T, Sanders L 1988, Comparing urban dynamics models:the unexpected differences in two similar models. Sistemi Urbani 2, 213-228.

Paulus, F. 2004. Coévolution dans les systèmes de villes : croissance et spécialisation des aires urbaines françaises de 1950 à 2000. Thèse de Doctorat, Université Paris 1 Panthéon-Sorbonne, Paris.

Paulus F., \& Vacchiani-Marcuzzo C. 2016, Knowledge industry and competitiveness: Economic trajectories of French urban areas (1962-2008) in Cusinato A., Philippopoulos-Mihalopoulos A. Knowledge-creating Milieus in Europe: Firm Cities, Territories. Springer, pp. 157-170.

Pinchemel P. Carrière F. 1963. Le fait urbain en France. Paris, A. Colin.

Pred A. 1973, Urban growth and the circulation of information : the United States system of cities, 1790-1840. Cambridge (Mass.), Harvard University Press.

Pred A. 1977, City systems in advanced societies. London, Hutchison.

Pumain D. 1982, La dynamique des villes. Paris, Economica, 231 p.

Pumain D. 1997, Vers une théorie évolutive des villes. L'Espace Géographique, 2, 119-134.

Pumain D. 1998, Les modèles d'auto-organisation et le changement urbain. Cahiers de Géographie de Québec, 117, 349-366.

Pumain D. 2004, Scaling laws and urban systems. Santa Fe Institute, Working Paper n04-02-002, 26 p.

Pumain D. 2008: The Socio-Spatial Dynamics of Systems of Cities and Innovation Processes: a MultiLevel Model in Albeverio S., Andrey D., Giordano P., Vancheri A. (Eds.) The Dynamics of Complex Urban Systems. An Interdisciplinary Approach. Heidelberg, Physica Verlag, 373-389.

Pumain D. 2009, L'espace, médium d'une construction spiralaire de la géographie, entre société et environnement, in Walliser B. (ed), La cumulativité des connaissances en sciences sociales. Paris, EHESS, collection Enquêtes, 163-197. 
Pumain D. 2012, Une théorie géographique pour la loi de Zipf. Régions et Développement, 36, 33-57.

Pumain D. 2018, An evolutionary theory of urban systems, in Rozenblat C. Pumain D. Velasquez E. 2018, International and Transnational Perspectives on Urban Systems. Springer Nature, Advances in Geographical and Environmental Sciences, 3-18.

Pumain D. Saint-Julien T., 1978, Les dimensions du changement urbain. Paris, CNRS, 202 p

Pumain, D., Paulus, F., Vacchiani-Marcuzzo, C., \& Lobo, J. (2006). An evolutionary theory for interpreting urban scaling laws. Cybergeo: European Journal of Geography, 343.

Pumain, D., Paulus, F., \& Vacchiani-Marcuzzo, C. (2009). Innovation Cycles and Urban Dynamics. In: Lane, D., Pumain, D., van der Leeuw, S., \& West GB. (eds). Complexity perspective in innovation and social change, Methodos series, Dordrecht: Springer, 237-260.

Pumain D. 2010, Dynamique des entités géographiques et lois d'échelle dans les systèmes complexes : la question de l'ergodicité. Mathématiques et Sciences Humaines, 191, 3, 51-63.

Pumain D. Sanders L. 2013, Theoretical principles in inter-urban simulation models: a comparison. Environment and Planning A, 45, 2243-2260.

Pumain D., Swerts E., Cottineau C. Vacchiani-Marcuzzo C., Ignazzi A., Bretagnolle A., Delisle F., Cura R., Lizzi L, Baffi S. 2015 : Multi-level comparison of large urban systems. Cybergeo, European Journal of Geography, 706.

Pumain D. Reuillon R. 2017, Urban Dynamics and Simulation Models. Springer, International. Lecture Notes in Morphogenesis, 123 p., DOI 10.1007/978-3-319-46497-8_3.

Reuillon, R., Schmitt, C., De Aldama, R., and Mouret, J. B. (2015). A new method to evaluate simulation models: the calibration profile (CP) algorithm. Journal of Artificial Societies and Social Simulation, 18(1), 12.

Rey-Coyrehourcq, S. (2015). Une plateforme intégrée pour la construction et l'évaluation de modèles de simulation en géographie. Doctoral dissertation, Paris 1-Panthéon-Sorbonne.

Reynaud J., 1841, «Villes », Encyclopédie nouvelle, t. VIII, Gosselin, 670-687.

Robson B. T., 1973, Urban growth, an approach. Methuen, London.

Rozenblat, C. 2018. Urban Systems Between National and Global: Recent Reconfiguration Through Transnational Networks in Rozenblat C. Pumain D. Velasquez E. (eds) International and Transnational Perspectives on Urban Systems, Springer, Singapore, 19-49.

Sanders, L. (1992). Système de villes et synergétique. Anthropos, Paris.

Sanders, L. 2013, Trois décennies de modélisation des systèmes de villes: sources d'inspiration, concepts, formalisations. Revue d'Économie Régionale and Urbaine, 5, 833-856.

Sanders L., Favaro J.-M., Mathian H., Pumain D., Glisse B., 2007, Intelligence artificielle et agents collectifs : le modèle EUROSIM, Cybergeo : European Journal of Geography, Dossiers, 392.

Schmitt, C. 2014, Modélisation de la dynamique des systèmes de peuplement: de SimpopLocal à SimpopNet. PhD thesis, Université Paris I-Panthéon-Sorbonne, Paris. 
Schmitt, C., Rey-Coyrehourcq, S., Reuillon, R., and Pumain, D. 2015, Half a billion simulations, evolutionary algorithms and distributed computing for calibrating the SimpopLocal geographical model. Environment and Planning B, 42(2), 300-315.

Vacchiani-Marcuzzo C. 2016, Is the South African urban system apart? Assessment of an Urban Hybridity, Habilitation à diriger des recherches, Université de Paris 1- Panthéon-Sorbonne, 202 p.

Weidlich W, Haag G (eds.), 1988 Interregional migrations. Dynamic theory and comparative analysis (Springer Verlag, Berlin) 